\title{
THE CHANGING DYNAMICS OF TALENT MANAGEMENT WITH MEDIATING ROLE OF ARTIFICIAL INTELLIGENCE AND DIGITALIZATION
}

\section{DR. DEEPIKA PANDITA}

Assistant Professor, Department of Human Resources Management, Symbiosis Institute of Business

Management Pune, Symbiosis International University, Pune, India

Talent management is an emerging area which is gaining interest by both industry and government. As we move toward building knowledge organizations, talent management will play a fundamental role towards the success of transforming individual knowledge into organizational knowledge. One of the key building blocks for developing and advancing this field of talent management is artificial intelligence, which many human resources management practitioners and theorists are overlooking. This paper will discuss the emergence and future of the talented management, and its link to artificial intelligence by digitalizing the processes of Human Resources.

KEYWORDS: Digitalization, Automation, Human Resources, Talent \& Artificial Intelligence
\end{abstract}

Received: Apr 20, 2019; Accepted: May 10, 2019; Published: Jun 06, 2019; Paper Id.: IJHRMRJUN201922

\section{INTRODUCTION}

For several years now we have been witnessing a transcendent digitization process. It impacts, clearly, on consumers and companies. The main technological transformation affects our habits, our way of relating. We are digitizing ourselves from inside out, transforming ourselves progressively from organizational systems and totally analog companies to new technical models that manage relationships with different stakeholders, culture, organization internally and the business.

Compared to other previous revolutions, the main difference with this revolution of digitalization and AI is that before the changes were generated through progressive improvements on certain ways of doing and producing, with greater or lesser efficiency. Now we evolve from organizational models of productive key to relational models that generate new results, this is only possible because now machines and codes do most of the work. Now one can focus entirely on generation of new material and ideas, and in turn more money.

Having more digital information, almost immediately, will significantly improve predictions and decision making. The levels reached by the technology are generating a level of automation, which combined with artificial intelligence or cognitive systems, present expectations that were previously unknown. Connectivity is reaching levels of connecting not only people, but also machines among themselves, in an intelligent way. The ability to digitally access the client, allows a degree of customization in the offer that otherwise would be unattainable.

\section{LITERATURE REVIEW}

Taking a closer look at the digitalization, it is defined as the digital representation of signals, information, and objects in binary code (e. g., Castells 2010), enabling computer processing as a basic technology and fostering 
convergence among technological applications of diverse fields of application. Digitalization has penetrated all spheres of life (Schmidt/Cohen 2013; Toygar/Rohm Jr./Zhu 2013), for example the contemporary media world, the contemporary business world or contemporary automated production. In the sense of spillover effects. It also offers benefits for traditional spheres by making more effective and more efficient resources available (McQuail 2010). Industry 4.0, the internet of things or ubiquitous computing make it a digital megatrend. But digitalization has also a dark side, since it created new inequalities between individuals, social groups, organizations and nations in regard to digitalization infrastructure, investments in technological equipment, and digitalization skills - the so-called "digital divide" (McQuail 2010: 555).

Human resources have various functions; out of which administration, compensation, reimbursements, leave management are already a norm in any company to have been digitized. What this has done is, not just take jobs away that are mundane in nature but also opened up opportunities for employees to part take in higher order functions of their department. Technological advancements have taken away time that we would spend on tasks and made us more efficient, smarter and has made the work and information reliable. The great challenge facing HR is how to make the most of artificial intelligence in order to provide the benefit conferred by this technology in favor of improving the experience of employees and business results.

The investment in new Artificial Intelligence projects has accelerated exponentially from 282 million dollars in 2011 to 2.4 billion dollars in 2015. Many of these projects are aimed at home or personal use, but many others for the business world. This situation positions HR with a bright perspective of incorporating this type of technology on a day-today basis and as the main axis of its digital transformation strategy.

Using technology for the development of digital human resources should not be the end, but the means to create practices aimed at improving the company's results and meeting strategic objectives. Do not advance in the digitalization, it would be troglodytes to try to avoid the tide of technological.

Connectivity is reaching levels of connecting not only people, but also machines among themselves, in an intelligent way.

In this rapid world of, result orientation companies have not just started adopting these technologies to make profit, or in profit making departments of their firm, for example, production, marketing or sales. But companies see the value in and realize the importance of digitalization in Human resources.

The exponential increase in connectivity opportunities between people, machines and products, completely changes the paradigm on which we have been working until now. The access basic technological developments give us have made the world a smaller place. For HR in firms for example, hiring the best for themselves is not for example limited to a pool of people who apply after seeing newspaper advertisements. Individuals can reach companies and companies can reach individuals through available platforms online that we cannot count.

\section{Purpose of the Study}

The purpose of this paper is to enhance the readers' understanding of the domain of talent management and the effect of AI and digitalization, and how the former culminates in the latter, specifically as a tool for retention of employees. The paper also attempts to probe and aid readers in understanding of the domain of talent management and digitalization, specifically as a tool to automate processes for better functioning of the organization. 


\section{METHODOLOGY}

To continue with our work on talent management and an endeavour to bring some clarity on the area of artificial intelligence and digitalization, this paper is based on a systematic review of literature on talent management with the mediating role of $\mathrm{AI}$ and digitalization which seeks to synthesize the current thinking and evidence. Literature for this study was predominantly sourced from internet searches and use of management journal databases such as EBSCO, EMERALD, Elsevier and SCOPUS.

\section{Findings}

Following are major findings that are driving decision making in human resources through artificial intelligence and digitalization.

\section{RATIONAL DECISION-MAKING}

Get-away demands - Employees that need to put in for get-away days are educated that it is probably not going to be affirmed the same number of others have effectively reserved excursion in that time period. Deciding your state of mind - A worker accepts a customer call. After the call, the worker gets input that he appears to be on the edge and should enjoy a reprieve before his gathering.

Group preparing- When an association needs to adopt a more orderly strategy to worker preparing, group administrators are given a rundown of preparing open doors for colleagues.

Procuring forms - An enlisting administrator is given data that the organization's enrolment approach misses the mark since it meets excessively few competitors. Psychological arrangements can enable associations to take advantage of different information sources and uncover new bits of knowledge to enable organizations to create competitor profiles, in addition to other things.

Automation of 'Redundant, less value Adding works'

HR investing energy preparing the means of on boarding another representative (designating space, provisioning a workstation, and so on.). Sparing time in those fields can help HR groups turn to ensuring they centre around" esteem include work like coaching and constant criticism."

AI apparatuses mechanize away normal HR assignments like advantages administration and triaging basic inquiries and solicitations, HR groups will be "allowed to accomplish a greater amount of the imaginative and vital work that beggarly affects the achievement of their organizations".

\section{AI RECRUITERS}

Candidates and employees anticipate that custom encounters custom-made will their one of a kind needs as they apply for another activity, pick the correct advantages or investigate advancement opportunities. Companies have actualized "AI spotters" to computerize booking interviews, give continuous criticism to hopeful and answer their inquiries progressively.

Identifying Employees on the Way Out

It tracks worker PC movement-messages, key strokes, web perusing, and so on-and stores it formulation 
month and executes an AI framework that dissects the information to decide a gauge of ordinary action designs in the association. "In light of that information," HRPA (Human Resources Professional Association specialists noted, "it banners exceptions and reports them to the business and furthermore distinguishes changes in the general tone of workers' correspondences to foresee when representatives may consider clearing out."

Using the Seed Link-algorithms have had a huge effect on L'Oréal's hiring process and success rate since. It is candidate potential that ultimately wins and not the university they come from or any other factor. Its pure potential that makes the difference. By knowing each individual's expectations, it becomes easier to measure their engagement and set out a personalised career path. On top of this, the data help to manage expectations and are universally accepted as a neutral selection tool. The efficiency and relevance-rating of L'Oréal's recruitment process has improved remarkably and since the job offer ratio for interviewed candidates is up to 82 percent.

With great technology comes great responsibility. Outsourcing of jobs to automated technology is a one of the prime shifts the world is noticing due to development of AI and other technology. "By some estimates, artificial intelligence will cause the loss of 7.1 million jobs across 15 leading economies over the next five years."

Moreover, there can be no improvement with Experience:

Unlike humans, artificial intelligence cannot be improved with experience. With time, it can lead to wear and tear. It stores a lot of data but the way it can be accessed and used is very different from human intelligence.

Machines are unable to alter their responses to changing environments. We are constantly bombarded by the question whether it is really exciting to replace humans with machines.

Recognizing and concentrate the danger of man-made brainpower is an imperative main job. This can help in settling the issues at hand. Programming mistakes or digital assaults require more devoted and watchful research. Technology organizations and innovation industry all in all needs to give careful consideration to the nature of the product. Everything that has been made in this world and in our individual social orders is the ceaseless consequence of insight.

Computerized reasoning expands and enables human intelligence. So as long we are fruitful in keeping innovation gainful, we will have the capacity to encourage this human progress.

For example, as chat bots improve, millions of customer service representatives around the world will lose their jobs. And as developers get better at automating certain parts of their jobs, they 're unwittingly replacing themselves.

The genuine trend-setters around AI in HR and enlisting, not withstanding, are those utilizing machine learning and prescient investigation to create objective and utility-based AI frameworks. By assessing hopeful qualities and data, AI can foresee who an association's future superior workers will be, who will remain at work longer, and who is destined to get an advancement. Moreover, machine learning-based AI can enable associations to stay away from possibly negative results related with contracting, as unfriendly effect against ensured bunches. While some dread that AI-driven employing will build homogeneity of race, sexual orientation, and ethnicity in a work environment, frameworks can be prepared to stay away from precisely those negative results while boosting legitimacy and positive prescient outcomes.

\section{AI-Driven Human Capital Management}

All things being equal, how about we consider two ideas upheld by AI ideas - better outcomes and computerization. Better outcomes: With AI, organizations have shown clear picks up in competitor view of the application 
encounter utilizing talk driven application usefulness. Also, machine learning procedures implanted in the application procedure has indicated huge outcomes over differentbusinesses around diminished turnover, expanded execution, and improved probability of advancement.

\section{ROBOTIZATION}

This makes the life of enrolment specialists less demanding. Through AI-driven procuring, spotters can focus in on the correct applicants speedier to rapidly and precisely recognize individuals for the following opportunity. Like Amazon's Alexa encourages us to put arranges all the more viably or select music that is most lined up with our taste, the capacities of AI can assist us with automating not just the way toward enlisting and applicant determination yet additionally progression arranging, representative improvement, and an abundance of different regions. It is an energizing time to be in HR. Associations contrast as much as the information they deliver. The advanced disturbance impacts an association and the business sectors on which it contends. This impacts the attitudes of progress and requires consistent alterations of the change way and the objectives that must be accomplished. But then, the hardest part is that everyone of these progressions must be set apart by unrest, not development. An undertaking or foundation can't stand to invest years tinkering with incremental process changes. Computerized change must be fast and irreversible, or else it is likely destined to disappointment.

Fruitful associations in the computerized age utilize any number of strategies to draw in and connect with toplevel ability. Having a solid brand and dynamic culture is normally a major help here, similar to the capacity to pay a premium for this ability. To get the correct representatives, advanced pioneers are progressively adjusting to the requests of best gifts as these workers look for non-conventional parts, benefits, motivating forces, rewards, compensation bundles, and work environment conditions.

Strengthening is completely basic to their inspiration. Center abilities (both inside and outside the association) must be given responsibility for activities and the slack to enhance their work environment encounters.

Strategically it develops energy well ordered. Starting with the enrollment procedure, to demonstrate whatever is left of the association what lies ahead by following the case. Finding the correct ability against low expenses and in less time, is an immense contention in the present association. In any case, corporate pioneers likewise need them to function admirably together and exhibit a solid social fit with the association. Their HR experts must encourage this as well.

In the corporate world, outstanding amongst other fields to put AI to great utilize are HR divisions, as the organization's' first line in managing the "human" segment of their organizations. In AI, they can locate an incredible partner at all phases of their expert work, from early short listing of gifts and candidates' screening to later on boarding methodology and execution appraisal. Notwithstanding expelling the unneeded weight from HR workforce, AI can help with streamlining these undertakings and increasing extraordinary bits of knowledge into the genuine execution capability of every applicant and worker. The majority of this is managed without the constraints of human predisposition and limit with regards to blunder, making AI a HR administration device without bounds, with benefits officially ready for picking. When filling positions is a period touchy need, it gets harder for enlistment to be circumspect. An absence of value ability causes an expansion in the levels of coordination and administration required, implying that efficiency goes down.

At the point when the enlisting accentuation is on quality and profitability, benefits increment for the association and in addition for its representatives. Individual's examination can bolster HR in social event information to decide the 
propensities and attributes of the most astounding performing individuals and groups. The discoveries of which can be utilized as a part of future enrollment and ability advancement.

\section{CONCLUSIONS}

It is foreseeable that companies will benefit from dynamization capabilities and digitalization fitness of their employees. Updating the human resources development towards digitalization leads to more anticipation, more proactivity and more modernity in order to break the vicious circle of missing the future. Overall, this new agenda will be able to contribute to the professionalization of the HR function (Stein 2010), making it less static and supporting it to cope with the increasing complexity of systems and of control (Scholz, T. M. 2013). In general, dynamization has influenced and will even stronger influence research. This is not primarily due to the fact that everything is becoming more dynamic, but due to the fact that technological progress allows us to cope with dynamization and to make up for lost time. Digital information systems are big and fast enough to deal with the big amount of data that accompanies the dynamic view. The focus on the dynamic future of the digitalized economy is expected

to raise the success of companies: Human resources development as well as further signals of future viability can make the difference if applicants decide between alternative employers. And it can make a difference, whether and how a company with all its change prepares employees for the digitalization megatrend (e. g., Rafferty/Jimmieson/Armenakis 2013). The very list of new digitalization-related professions such as Social Media Manager, Community Manager, Chief Experience Officer, Online Reputation Manager, Gamification Designer, Augmented Reality Architect, Crypto-Currency Banker and Telecop (Pein 2014) indicates the upcoming changes in the corporate world. Companies have the opportunity to shape this dynamic future now. Addressing implications for future research, due to the conceptual nature of this article, validation of the proposed human resources development agenda will become necessary. Empirical longitudinal analysis will be able to assess the long-term qualitative advancements of a human resources development that focuses on digitalization. Furthermore, it will be interesting to see how big data can be used in that process. Many of the underlying dynamics even of human resources development are still hidden but can eventually be discovered by linking data that has not been linked before. Although this calls for an inductive research method, big data will sooner or later infiltrate the HRM

\section{REFERENCES}

1. Ali, S./Peters, L. D./Lettice, F.(2012): An Organizational Learning Perspective on Conceptualizing Dynamic and Substantive Capabilities, in: Journal of Strategic Marketing 20(7),589-607.

2. Castells, M. (2010): The Information Age. Economy, Society and Culture. VolumeI: The Rise of the Network Society, 2nd ed., Chichester: Wiley-Blackwell.

3. Dörner, D. (1989): DieLogikdes Mißlingens. Strategisches Denkeninkomplexen Situation en, Reinbekbei Hamburg: Rowohlt.

4. Doz, Y.; Kosonen, M. (2010): Embedding Strategic Agility: A Leadership Agenda for Accelerating Business Model Renewal, in: Long Range Planning 43(2-3),370-382.

5. Farjoun, M. (2010):Beyond Dualism: Stability and Change as a Duality, in: Academy of Management Review 35 (2),202-225.

6. Findler, D./Gorbis, M.(2013):10 New Skills that Every Worker Needs, in: Rotman Magazine (3),40-45.

7. GfKEnigma (201m frageinmielstndischennternehmenum The maigitalisierung-Bedeutungfrden Mittelstand im Auftrag der DZ Bank, in: 
8. Hugill, A./Smith, S.(2013): Digital Creativity and Transdisciplinarity at Postgraduate Level: The Design and Implementation of a Transdisciplinary Masters Programme and its Implications for Creative Practice, in: Digital Creativity 24(3),191-207.

9. Krill, M.(2014): Mitarbeiterbindungim Einflussfeldgesellschaftlicher Modernisie rung in Mittel-und Osteuropa, Frankfurtam Main: PeterLang.

10. Lewis, M. W. /Andriopoulos, C./Smith, W. K.(2014): Paradoxical Leadership to Enable Strategic Agility, in: California Management Review 56(3),58-77.

11. Littlejohn, A./Beetham, H./McGill, L. (2012): Learning at the Digital Frontier: A Review of Digital Literacies in Theory and Practice, in: Journal of Computer Assisted Learning 28(6),547-556.

12. McQuail, D. (2010): McQuail's Mass Communication Theory, 6th ed., Los Angeles etc.: Sage. Pein, V. (2014): Berufsbilderder Zukunft, in: t3n Magazin 10(37), 58-61.

13. Rafferty, A. E./Jimmieson, N. L./Armenakis, A. A. (2013): Change Readiness: A Multilevel Review, in: Journal of Management 39(1), 110-128.

14. Schmidt, E./Cohen, J. (2013):The New Digital Age: Reshaping the Future of People, Nations and Business, New York: Alfred A. Knopf.

15. Scholz, C. (2000): Strategische Organisation. Prinzipienzur Vitalisierungund Virtualisierung, 2nd ed., Landsberg/Lech: modern industries.

16. Scholz, T. M. (2013): Complex Systems in Organizations and Their Influence on Human Resource Management, in: Gilbert, T./Kirkilionis, M./Nicolis, G.(eds.): Proceedings of the European Conference on Complex Systems. Heidelberg: Springer, 745750.

17. Selwyn, N. (2012): Making Sense of Young People, Education and Digital Technology: The Role of Sociological Theory, in: Oxford Review of Education 38(1), 81-96.

18. Sha, L./Looi, C.-K./Chen, W./Zhang, B. H. (2012): Understanding Mobile Learning from the Perspective of Self-regulated Learning, in: Journal of Computer Assisted Learning 28(4),366-378.

19. Simões, Jorge/Redondo, R. D./Vilas, A. F. (2013): A Social Gamification Frame work for a K-6 Learning Platform, in: Computers in Human Behavior 29(2), 345-353.

20. Stein, V. (2009): Kondratiew-Zyklus, in: Scholz, C.(ed.), Vahlens Gro ßes Personallexikon, Munich: C. H. Beck/Vahlen, 603604.

21. https://www.linkedin.com/pulse/5-criteria-sorting-through-seemingly-endless-hr-dave-ulrich/.

22. https://www.forbes.com/sites/forbestechcouncil/2018/05/09/how-ai-is-transforming-hr-departments/\#605145101c0f

23. https://analyticsindiamag.com/top-use-cases-ai-human-resources/

24. https://www.hrci.org/community/blogs-and-announcements/hr-lea ds-business-blog/hr-leads- business/2018/04/11/the-futureof-hr-big-on-artificial-intelligence

25. https://www.personneltoday.com/hr/ten-ways-hr-tech-leaders-canmake-artificial-intelligence/

26. https://www.entrepreneur.com/article/312152

27. https://www.cio.com/article/3263450/artificial-intelligence/artificial-intelligence-gives-hr-an-opportunity-to-transform-theenterprise. html 
28. https://www.forbes.com/sites/jeannemeister/2017/11/09/the-futureof-work-how-artificial-intelligence-will-transform-theemployee-experience/\#6ea05e3e23c9

29. https://www.cmswire.com/digital-workplace/7-ways-artificial-intelligence-is-reinventing-human-resources/

30. https://www.pwc.at/de/publikationen/verschiedenes/artificial-intelligence-in-hr-a-no-brainer.pdf

31. https://interestingengineering.com/programmer-automates-job-6-years-boss-fires-finds

32. https://content.wisestep.com/advantages-disadvantages-artificial-in telligence/ 